\title{
Linking Life-History Traits, Ecology, and Niche Breadth Evolution in North American Eriogonoids (Polygonaceae)
}

\author{
Anna Kostikova, ${ }^{1,2,3}$ Glenn Litsios, ${ }^{1,2}$ Nicolas Salamin, ${ }^{1,2, x, \dagger}$ and Peter B. Pearman ${ }^{3, \dagger}$ \\ 1. Department of Ecology and Evolution, University of Lausanne, 1015 Lausanne, Switzerland; 2. Swiss Institute of Bioinformatics, \\ Quartier Sorge, 1015 Lausanne, Switzerland; 3. Landscape Dynamics, Swiss Federal Research Institute WSL, 8903 Birmensdorf, Switzerland \\ Submitted January 11, 2013; Accepted July 9, 2013; Electronically published October 17, 2013 \\ Online enhancement: supplementary information. Dryad data: http://dx.doi.org/10.5061/dryad.46kv1.
}

ABSTRACT: Macroevolutionary and microevolutionary studies provide complementary explanations of the processes shaping the evolution of niche breadth. Macroevolutionary approaches scrutinize factors such as the temporal and spatial environmental heterogeneities that drive differentiation among species. Microevolutionary studies, in contrast, focus on the processes that affect intraspecific variability. We combine these perspectives by using macroevolutionary models in a comparative study of intraspecific variability. We address potential differences in rates of evolution of niche breadth and position in annual and perennial plants of the Eriogonoideae subfamily of the Polygonaceae. We anticipated higher rates of evolution in annuals than in perennials owing to differences in generation time that are paralleled by rates of molecular evolution. Instead, we found that perennial eriogonoid species present greater environmental tolerance (wider climate niche) than annual species. Niche breadth of perennial species has evolved two to four times faster than in annuals, while niche optimum has diversified more rapidly among annual species than among perennials. Niche breadth and average elevation of species are correlated. Moreover, niche breadth increases more rapidly with mean species elevation in perennials than in annuals. Our results suggest that both environmental gradients and life-history strategy influence rates and patterns of niche breadth evolution.

Keywords: niche breadth, intraspecific variability, latitudinal niche breadth hypothesis, elevation, phylogeny, Eriogonoideae, climatic niche evolution.

\section{Introduction}

The evolution of the ecological niche (Hutchinson 1957) is a fundamental research topic for ecologists and evolutionary biologists. The mode and tempo of niche evolution play important roles in adaptation of species to novel environments (Losos and Ricklefs 2009), influence diversification patterns through speciation and extinction rates

\footnotetext{
* Corresponding author; e-mail: nicolas.salamin@unil.ch.

${ }^{\dagger}$ N. Salamin and P. B. Pearman led this study and supervised A. Kostikova. Am. Nat. 2013. Vol. 182, pp. 760-774. (C) 2013 by The University of Chicago. 0003-0147/2013/18206-54395\$15.00. All rights reserved. DOI: $10.1086 / 673527$
}

(Kozak and Wiens 2010), and contribute to diversity in species communities (Cavender-Bares et al. 2009). At least two niche components contribute differentially to species evolution. On the one hand, each species can occupy a unique fitness optimum along an environmental gradient (Wright 1932). On the other hand, species differ considerably in the degree of niche specialization, with a wider niche signifying greater dispersion of resource use or broader environmental tolerance (Futuyma and Moreno 1988). Understanding the evolutionary dynamics of the niche as an empirical multivariate distribution along diverse types of gradients and variables requires investigation of both niche components.

The evolution of niche breadth, expressed as intraspecific variation in niche occupancy (Colwell and Futuyma 1971), has received less attention in comparison with that focused on niche position. Despite the extensive literature examining niche breadth through the prism of adaptive evolutionary dynamics in in vitro systems (Brown and Pavlovic 1992; Holt 1992; Kassen 2002), only rarely has the evolution of intraspecific niche variation been considered in natural systems, at least ones with more than a handful of species (Ingram et al. 2009; Caitlin Fisher-Reid et al. 2012). Exclusive focus on the evolution of niche position is problematic when species have complex lineage structure, and these lineages differ in their niche characteristics (Pearman et al. 2010). Further, evolution of niche breadth in communities impacts community composition and ecosystem structure and function (Pianka 1974). For instance, the identification of intraspecific niche variation is particularly relevant in examination of groups experiencing ongoing speciation (Kocher 2004), in understanding the ecological diversification of phylogenetically younger clades (Evans et al. 2009), and in discerning mechanisms underlying species range expansion and/or rapid (local) adaptation (Urbanski et al. 2012). Immense variation in niche breadth among species suggests that increased focus on the evolution of niche breadth can 
provide insight regarding the evolutionary origins of ecological variation. Moreover, because niche breadth is a character that expresses intraspecific variability, understanding the evolutionary dynamics of niche breadth likely requires integrating both intraspecific (microevolutionary) and interspecific (macroevolutionary) perspectives.

From a microevolutionary perspective, the contributions of distinct genetic mechanisms to the evolution of niche breadth are not entirely clear (Kassen 2002). For example, in experimental populations of Escherichia coli grown under distinct thermal conditions, antagonistic pleiotropy drives negative genetic correlations in fitness across environments, limiting the evolution of niche breadth (Futuyma and Moreno 1988; Bennett and Lenski 2007). Further, accumulation of deleterious mutations with habitat-specific expression can impair the competitive ability of generalist species against specialists (Kawecki 2000). Rates of molecular evolution also provide an additional level of complexity but have been considered only rarely in existing theories of niche breadth evolution (e.g., for allelic fixation rates; Whitlock 1996; Kassen 2002). Rates of molecular and niche breadth evolution are likely connected because higher rates of molecular evolution increase the fixation rates of alleles with environmentspecific effects, thus influencing the rates at which species adapt and specialize (Whitlock 1996). In addition, amongspecies variability in rates of molecular evolution is partly associated with species life-history traits, such as age at first reproduction, number and size of offspring, and reproductive life span and generation time (Tsantes and Steiper 2009; Lanfear et al. 2010). For example, adding a longlived stage in two-stage populations leads in theory to lower rates of adaptive evolution (Barfield et al. 2011). Thus, these life-history properties should be explicitly accounted for when testing hypotheses on the relationships between macroecological variation and rates of molecular and niche evolution. Finally, while rates of evolution of niche optima are negatively correlated with species generation time and positively with molecular rates (Smith and Beaulieu 2009), the extent to which these two characteristics shape evolution of niche breadth remains unaddressed.

From a macroevolutionary perspective, theory predicts that niche breadth evolution is associated with existing latitudinal variation in environmental stability, and in general, generalization should increase toward the poles, where populations experience the highest environmental instability (MacArthur 1965, 1972). For instance, empirical research shows that host specificity, with the number of hosts being equated to niche breadth, decreases with latitude in Palearctic flea species (Krasnov et al. 2008). Further, the existence of latitudinal gradients in the diversity of avian lineages leads temperate species to have larger ranges and span broader ecological gradients than do tropical species (Salisbury et al. 2012). In contrast, metastudy of 12 major taxa of mammals, birds, and insects (Vázquez and Stevens 2004) shows that niche breadth has evolved to increase with latitude in only two species groups, while five groups display the reverse relationship and five reveal no significant pattern. Similarly, the niche breadth of species may increase with the mean elevation of their distribution (Rasmann et al. 2014). For example, generalism in feeding habits of two groups of herbivorous and nectivorous insects (Buprestidae and Apiformes, respectively) increases with elevation (Pellissier et al. 2012; Rasmann et al. 2014). In contrast, ant communities of the Mojave Desert have relatively constant trophic niche breadths, regardless of elevation (Bernstein and Gobbel 1979). These results suggest that environmental variation that is associated with latitude or elevation may be mechanistically associated with evolved patterns of niche breadth but that the relationship appears group specific.

The Eriogonoideae subfamily (Polygonaceae), which constitutes $\sim 325$ species (Kempton 2012), is an excellent group to investigate questions regarding niche evolution. Growth forms of eriogonoids include tiny, fragile annuals; herbaceous perennials; low shrubs; and large, arborescent shrubs (Reveal 1978). The members of the Eriogonoideae are restricted to xeric regions of the New World, with most species confined to the western half of central North America, from the Tropic of Cancer northward to the fiftieth parallel. Ecologically, eriogonoids span broad latitudinal and altitudinal gradients, occur from the seashore to alpine environments, and reach the vegetation limit in lowelevation deserts. About one-third of the species are uncommon to rare in their distribution (Reveal 1978).

In this article, we examine the evolution of climatic niche position and niche breadth in the Eriogonoideae in relation to generation time and macroecological correlates such as latitude and elevation. First, we test whether rates, optima, and selection strength on climatic niche evolution differ between annual and perennial species. We regard niche breadth as intraspecific variation in niche occupancy and do not discuss the role of between-individual niche breadth variation in niche evolution (Bolnick et al. 2003), owing to the lack of experimental data. We focus on climate tolerance as a measure of the breadth of the species environmental niche, because this measure accounts simultaneously for multiple phenotypic traits (Smith and Beaulieu 2009). We use annual and perennial classes as a proxy for generation time. The assumption that annuals and perennials have different generation times is supported by many empirical studies (Hamrick et al. 1979; Andreasen and Baldwin 2001; Whittle and Johnston 2003; Soria-Hernanz et al. 2008; Duminil et al. 2009). With few exceptions and unlike annual species, perennial Eriogo- 
noideae species do not flower in their first year (Reveal 1978; Freeman 2005), which is a basic prerequisite for the differences in generation time. Second, we investigate whether differences in rates of climatic niche breadth evolution can be explained by the latitudinal or elevational positions of species. To address these questions, we use phylogeny-based evolutionary modeling and reconstructions of climate niche and geographical range. Our results suggest that rates of climatic niche breadth evolution are at least three times higher in species with longer generation times (i.e., in perennials compared with annuals) and such differences cannot be explained as anticipated by differences in species relative latitudinal position. In contrast, the evolution of climatic niche breadth is associated with elevational differences between annual and perennial species. Our results suggest that both environmental gradients and life-history strategies influence the rates and patterns of niche breadth evolution.

\section{Methods \\ Climatic Niche Modeling, Niche Breadth, and Geographical Range Estimations}

We obtained locality data (SI 1a [SI 1-13 available online]; average of 342 localities per species, ranging from 18 for Eriogonum contorum to $>2,900$ for Eriogonum fasciculatum) from Calflora, the Consortium of California Herbaria, and the Global Biodiversity Information Facility databases for 68 species (underlying data and SI are available in the Dryad Digital Repository: http://dx.doi.org/10.5061 /dryad.46kv1; Kostikova et al. 2013). While we analyze only a quarter of the Erigonoideae species, these species cover most of the geographic distribution of all Eriogonoideae species and are representative of Eriogonoideae taxonomic ( $25 \%$ of species from each subgenus), life history (approximately two-thirds of annuals and approximately one-third of perennials), and niche diversity (SI $1 b$, SI 1c). We obtained climatic layers at a resolution of 30 arcseconds from the WorldClim database (Hijmans et al. 2005). We generated pseudo-absence points $(2,500$ points per species) with nonstratified random sampling over the entire study area (SI 1d) using ArcGIS 10 (Environmental Systems Research Institute, Redlands, CA). Because we used observational data, we conducted climatic niche modeling of the species realized niche and not the fundamental niche, which would have required experimental methods on a large number of species (Hutchinson 1957). We conducted ensemble niche modeling using regression trees (CART) and random forests (RF) algorithms. Because CART/RF are insensitive to correlated predictors (Breiman 2001; Strobl et al. 2008; Nicodemus et al. 2010), we kept all 19 bioclimatic variables at the niche modeling stage but summarized them as principle components for evolutionary modeling (see below). The models were estimated in R (R Development Core Team 2011) using the trees (Ripley 2012), randomForest (Breiman and Cutler 2012), raster (Hijmans and van Etten 2012), and rgdal (Keitt et al. 2012) packages. We followed a published procedure (Cutler et al. 2007) for RF involving 500 trees and $20 \%$ of the training data set held out for the model performance assessment. We used a bagging approach (Breiman 2001) for CART to create more generalized and stable classification models. Training data were sampled 500 times, each time extracting $50 \%$ of the training data set with replacement. We estimated the probability of species presence by averaging the 500 classification results. Model performance was tested against the remaining 50\% of the data set.

We integrated the probability grids from climatic niche modeling with respect to each original climatic variable to estimate species-specific distributions for each variable (Evans et al. 2009). We then sampled randomly with replacement from these distributions 2,000 values from between the $2.5 \%$ and $97.5 \%$ quantiles and summarized these values on the first three principal component (PC) axes (Ade4 package; Dray and Dufour 2007). We then extracted from each PC species-specific niche position and niche breadth values, where niche positions were the weighted average values for a given species and niche breadths were the variances of species PC scores. These weighted values were calculated using OMI analysis (Doledec et al. 2000; Thuiller et al. 2004). We used Pearson $\chi^{2}(1$ and $3 \mathrm{df})$ and the Lilliefors (Kolmogorov-Smirnov) statistics (Thode 2002) to test the species-specific PC scores for normality and appropriateness for subsequent comparative analysis. We examined the distributions visually to confirm unimodality.

To assess the relationship between the life-history trait and latitude or elevation, we extracted coordinates and elevation values from the WorldClim elevation data set for all species occurrence records. We then calculated mean latitude for annual and perennial life-history classes in two ways. First, we extracted latitude coordinates for each occurrence record, pooled them for each class, and averaged. Second, we computed a centroid for each polygon of species range maps and then pooled data by life-history class to obtain averaged values using ArcGIS 10. Because we had extensive occurrence records for all species, we estimated species ranges directly from these data instead of using modeled species distributions. We minimized uncertainty by calculating species range maps in terms of area of occupancy and extent of occurrence (Gaston 1994). We manually digitized distribution polygons comprising all the occurrence records for a given species to obtain the area of occupancy of the species. We kept multiple poly- 
gons when isolated populations or discontinuous spatial ranges were observed. A convex hull was created for each species to obtain the extent of occurrence records. The same approaches were used to calculate species elevational positions for the two life-history classes.

\section{Phylogenetic Reconstruction and Molecular Dating}

We reconstructed a phylogeny based on two plastid genes (matK, $n d h F)$, two plastid intergenic regions ( $r b c L-a c c D$, $\operatorname{trnL}$-trnF), and two nuclear genes (5.8-ITS-18S block, $L F Y)$ to assess phylogenetic relationships among the 68 taxa of Eriogonoideae. The data were compiled from sequences available in GenBank (mean sequence length of the concatenated sequence, 2,200 base pairs; range, 4196,904; median, 1,694.5) and supplemented by our own sequences (Dryad data: http://dx.doi.org/10.5061/dryad .b9m853tp). Four outgroup species-Oxyria dygina, Fagopyrum esculentum, Fagopyrum gracilipes, and Fagopyrum tataricum - were further added to the DNA matrix (Sanchez and Kron 2008). The DNA matrix was aligned with Mafft (ver. 6; Katoh and Toh 2008) using the default settings and then adjusted by hand to maintain the amino acid reading frame in $m a t K$ and $n d h F$ exons. We ran Gblocks (Talavera and Castresana 2007) with default settings to eliminate poorly aligned positions and divergent regions of the DNA alignment. The GTR $+\Gamma$ model of sequence evolution was selected on the basis of the Akaike information criterion (AIC) for all DNA regions. Maximum likelihood analysis was done with PhyML (ver. 3.0; Guindon et al. 2009) using the SPR branch swapping algorithm and $10^{3}$ bootstrap replicates to assess node support. We determined the tree topology by Bayesian inference with MrBayes 3.1.2 (Ronquist and Huelsenbeck 2003) before conducting the divergence time analysis. We obtained the posterior distribution of phylogenetic trees with GTR $+\Gamma$ parameters being unlinked for the plastid genes, plastid intergenetic regions, and nuclear genes (three GTR $+\Gamma$ estimates in total). We repeated the MrBayes analyses four times and determined convergence by examining trace plots of each parameter in Tracer (ver. 1.4). Each analysis consisted of four chains of $10^{8}$ generations, sampling every $10^{3}$ steps.

Divergence time analysis was performed in BEAST (ver. 1.4.7; Drummond and Rambaut 2007). The root of the group was constrained by setting a normally distributed prior with a mean of 23.5 million years and a standard deviation of 4.5 million years (SI 2). One more internal node (root of Chorizanthe clade) was constrained with a fossil age obtained from the Paleobiology database (http: //paleodb.org; SI 2). We placed this fossil on the root of the Chorizanthe clade according to the topology retrieved from the MrBayes analysis (e.g., the Chorizanthe clade ex- cluding Chorizanthe spinosa and Chorizanthe rigida species). The BEAST analysis was run using a random starting tree for $10^{8}$ generations sampling every $10^{3}$ generations under the uncorrelated lognormal relaxed clock model, the Yule tree prior, and the GTR $+\Gamma$ model of substitution (same partitioning as for the MrBayes analysis). The analyses were repeated four times to verify convergence by examining the posterior distribution of parameters in Tracer. All subsequent analyses (see below) were done on a sample of 100 trees randomly drawn from the posterior distribution of dated trees after removing a burn-in of 3,000 trees. A consensus tree for graphical purposes was calculated after the removal of a burn-in period $(30 \%$ or 3,000 samples), which was determined by examining trace plots in Tracer. In addition, the tree log files with branch lengths in nucleotide substitutions were recorded for subsequent calculation of rates of molecular evolution per branch.

\section{Evolutionary Modeling}

We conducted an evolutionary analysis with respect to the life-history trait (annuals and perennials), used as a proxy for generation time. This trait was determined for all eriogonoid species using the Flora of North America (SI 3; Freeman 2005). We performed a phylogenetic ANOVA (Revell 2012) to determine whether latitudinal, elevational, and niche positions - as well as niche breadth and species geographical ranges-differed between annuals and perennials. We tested the relationship between niche breadths and mean latitudinal or elevational positions using a phylogenetic GLM model (Orme et al. 2011), with niche breadth serving as the dependent variable, latitude or elevation as the independent ones, and the life-history trait as a covariate.

We compared the fit of the following models to determine the necessary level of model complexity to describe niche evolution using the OUwie package (Beaulieu et al. 2012): (1) a Brownian motion model of evolution with a single rate parameter $\sigma$ (BM1; Felsenstein 1985); (2) a Brownian motion model with two rate parameters $\sigma_{\mathrm{a}}$ and $\sigma_{\mathrm{p}}$, estimated independently for annuals and perennials (BMS; O’Meara et al. 2006); (3) an Ornstein-Uhlenbeck model with a single trait optimum parameter $\theta$ (OU1; Hansen 1997); (4) an Ornstein-Uhlenbeck model in which trait optimum parameters $\theta_{\mathrm{a}}$ and $\theta_{\mathrm{p}}$ were estimated separately between the annuals and perennials (OUM; Butler and King 2004); (5) an expanded Ornstein-Uhlenbeck model in which both the rate parameters $\sigma_{\mathrm{a}}$ and $\sigma_{\mathrm{p}}$ and the trait optima parameters $\theta_{\mathrm{a}}$ and $\theta_{\mathrm{p}}$ could differ between the annuals and perennials (OUMV; Beaulieu et al. 2012); (6) Ornstein-Uhlenbeck models that assume different strength of selection $\alpha_{\mathrm{a}}$ and $\alpha_{\mathrm{p}}$ between annual and pe- 
rennial species (OUMA; Beaulieu et al. 2012); and (7) an expanded Ornstein-Uhlenbeck model in which both the rate parameters $\sigma_{\mathrm{a}}$ and $\sigma_{\mathrm{p}}$ and the strength of selection parameters $\alpha_{\mathrm{a}}$ and $\alpha_{\mathrm{p}}$ could vary between annuals and perennials (OUMVA; Beaulieu et al. 2012). We applied the same set of seven models to analyze separately the evolution of niche position and niche breadth.

Five models (BMS, OUM, OUMV, OUMA, OUMVA) in the analysis required ancestral state reconstructions of a categorical trait (i.e., whether a particular branch belongs to the annual or perennial state). We obtained these ancestral states estimates using stochastic mapping (Revell 2012). Two models of discrete trait evolution (symmetrical and asymmetrical) were assessed with the ace function (Paradis et al. 2004), and the best-performing model was used in subsequent analysis. Stochastic mapping was run 10 times for each of the 100 trees to further account for possible uncertainty in the estimated values. Finally, we calculated an average AIC weight and lower $(2.5 \%)$ and upper (97.5\%) quantiles of the distributions of AIC weights for each evolutionary model. We used stochastically mapped ancestral reconstructions of the life-history trait to calculate the mean molecular rate for each lifehistory class because the rates of molecular evolution obtained from BEAST analysis are branch specific. The estimated ancestral reconstructions were rescaled to branch-wise proportions and then summarized for each life-history class.

\section{Results}

Climatic Niche Modeling, Niche Breadth, and Geographical Range Estimations

Values of the area under the receiver operating characteristic curve for climatic niche models range from 0.92 to 0.99 (SI 4), confirming very good model performance (Swets 1988). Overall, the precipitation and maximum temperature of the wettest quarter have the highest relative importance in the models fitted by CART/RF (SI 5). The first (PC1), second (PC2), and third (PC3) componentsextracted from the probability grids-explain $43.42 \%$, $30.82 \%$, and $8.48 \%$ of the variation, respectively. PC1 is most strongly correlated with temperature seasonality, isothermality, and mean annual temperature (BIO3, BIO4, and BIO1 WorldClim variables), while PC2 represents precipitation and temperatures during the wettest and warmest seasons (BIO16, BIO8, BIO5, and $\mathrm{BIO} 10$ ), and PC3 represents a precipitation and isothermality gradient (BIO17, BIO18, BIO19, and BIO3). All PC scores of species, except for Chorizanthe spinosa and Chorizanthe rigida, are unimodal and, in the majority of cases $(86 \%)$, not different from a normal distribution (SI 6). Thus, the mean and variance values are adequate for phylogenetic comparative analysis as proxies for niche positions and niche breadths (SI 7). In the remaining $14 \%$ of cases, we reject the normality hypothesis but find that the kurtosis and skewness of the distributions are not significantly different from the normal expectation (SI 8). The distributions of PC scores for C. spinosa and C. rigida are not unimodal, and these two species are excluded from further analyses.

The area of occupancy and the extent of occurrence of species express correlated estimates of species geographical ranges (SI 9; $r_{2,66}=0.76, P<.001$ ), suggesting that either estimate could be used for modeling. We consider only area of occupancy in further analysis. Mean latitudinal
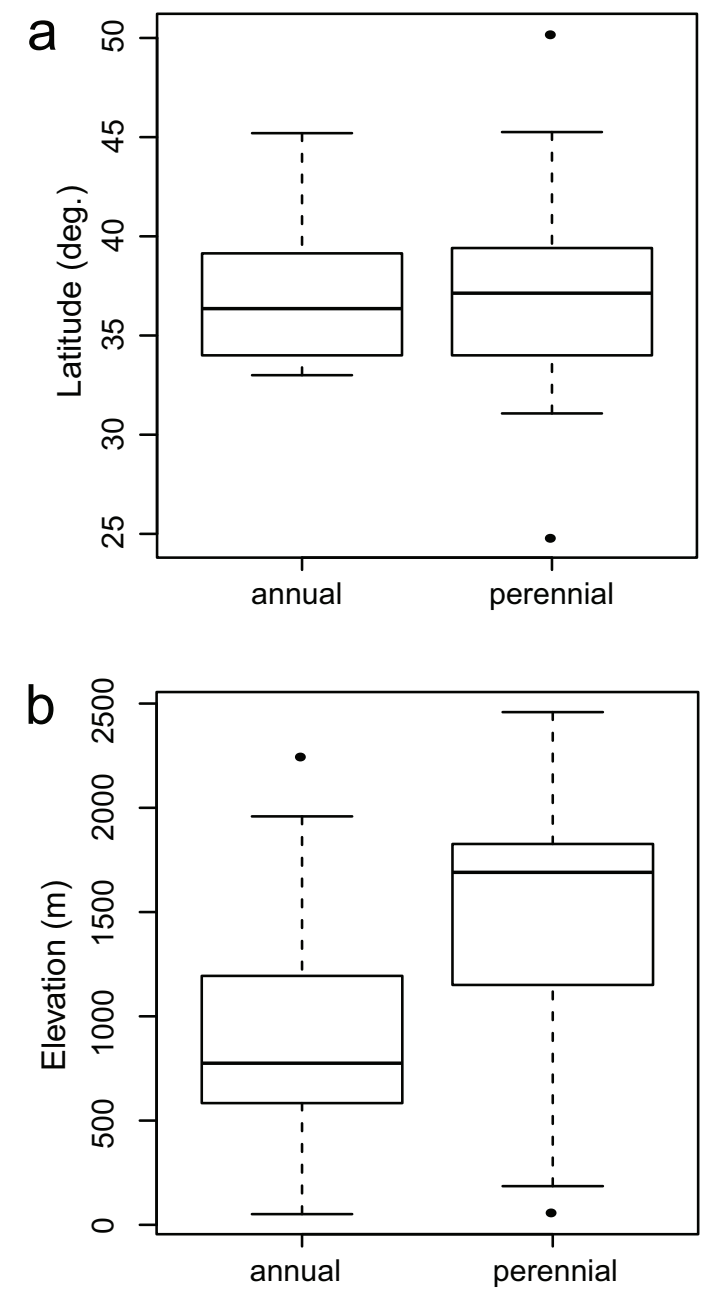

Figure 1: Box and whisker plots showing the latitudinal $(a)$ and elevational $(b)$ differences between annual and perennial species (medians, upper/lower quartiles, and whiskers of $\times 1.5$ interquartile range are shown). Latitudinal and elevational position have been measured for each occurrence record and then averaged for each species. 

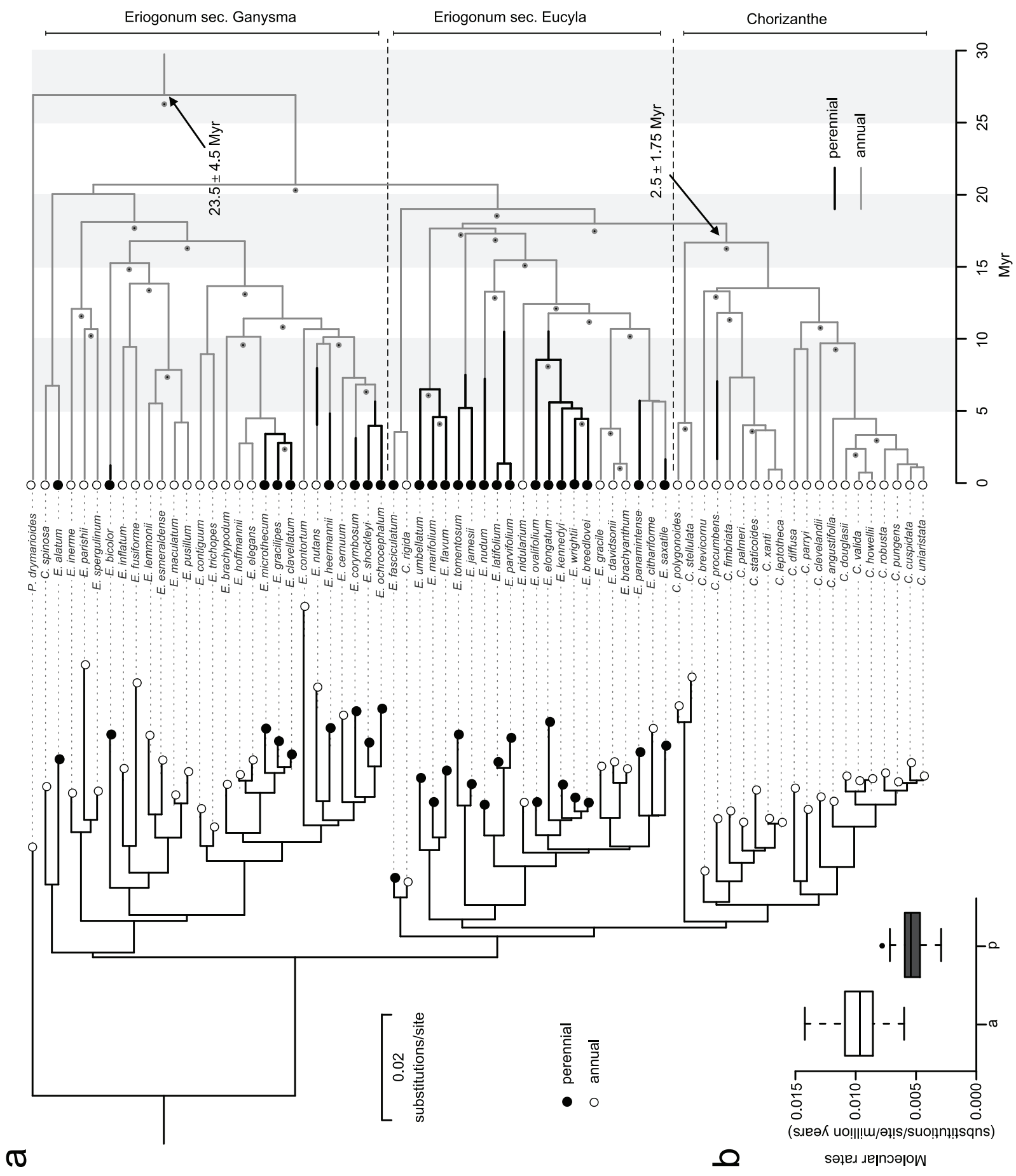
position, calculated either as a centroid from range polygons or as an estimate of latitudinal position from the occurrence records (SI 10), does not differ between annual and perennial species $\left(F_{2,66}=3.12, P=.92\right.$; fig. $\left.1 a\right)$. In contrast, the mean elevation of perennial species is significantly greater than that of annual species $\left(F_{2,66}=\right.$ 13.44, $P<.05$; fig. $1 b)$. We find no evidence for range size differences between perennial and annual species $\left(F_{2,66}=9.26, P=.071\right)$.

\section{Phylogenetic Reconstruction and Molecular Dating}

Both maximum likelihood and Bayesian inference analyses result in congruent topologies with good or moderate node support, with most of the nodes having a posterior probability $>0.9$ and bootstrap values $>80 \%$ (fig. $2 a$, nodes with black dots). The Eriogonum and Chorizanthe genera are not monophyletic in both maximum likelihood and Bayesian inference analyses, which is consistent with previous studies (Sanchez and Kron 2008; Kempton 2012). Pterostegia drymarioides is an outgroup lineage relative to Eriogonoideae, originating 18-31 million years ago (95\% highest probability density). Most cladogenesis events in Eriogonoideae occurred during the past 15 million years (fig. 2a). Molecular rates estimated from the phylogeny are 1.5 higher in annuals than in perennials (fig. $2 b$ ).

\section{Evolutionary Analysis}

The phylogenetic ANOVA of the relationship between niche breadth and the life-history trait reveals wider niche breadth in perennials than in annuals consistently on all ordination axes (table 1; SI 11). On average, the niche positions of annuals and perennials do not differ along the temperature seasonality/isothermality (PC1) or the precipitation/isothermality (PC3) gradients (table 1). In contrast, the perennials occupy colder niches than do annual species (PC2; table 1). The phylogenetic GLM model confirms that perennial species have wider climatic niches than do annuals (fig. 3). The slope of the regression of niche breadth on mean elevation is positive along all three PC axes (fig. 3; PC1: $F_{1,68}=30.14, P<.001$; PC2: $F_{1,68}=26.81, P<.001 ;$ PC3: $\left.F_{1,68}=7.66, P<.001\right)$ and differs between annuals and perennials (table 2). We do
Table 1: Phylogenetic ANOVA table for niche position and niche breadth differences between annual and perennial Eriogonoideae species

\begin{tabular}{lcrrrr}
\hline & $F$ & $\mathrm{SS}$ & $\mathrm{MS}$ & $\mathrm{df}_{\text {effect }}$ & $\mathrm{df}_{\text {residuals }}$ \\
\cline { 1 - 4 } Niche position: & & & & & \\
$\quad$ PC1 & 2.855 & 7.879 & 182.151 & 2 & 66 \\
PC2 & $19.487^{* *}$ & 31.253 & 105.851 & 2 & 66 \\
PC3 & .405 & .247 & 40.219 & 2 & 66 \\
Niche breadth: & & & & & \\
PC1 & $21.178^{* *}$ & 1.345 & 4.191 & 2 & 66 \\
PC2 & $20.359^{* *}$ & 1.681 & 5.447 & 2 & 66 \\
PC3 & $22.889^{*}$ & 2.912 & 10.646 & 2 & 66 \\
\hline
\end{tabular}

Note: Results from phylogenetic ANOVA showing the significance of differences in niche position and niche breadth between annual and perennial species. The niche breadth of perennial species differs significantly from the niche breadth of annual species across all principal component (PC) axes. For niche position, only PC2 is significantly different between these two classes.

${ }^{*} P<.05$.

${ }^{* *} P<.01$.

not detect any effects of latitudinal position on niche breadth (SI 12).

The asymmetrical model of character change used to model the evolution of annuals and perennials does not differ significantly from the symmetrical model (AIC 25.21 and 23.46, respectively; $\triangle \mathrm{AIC}<2$ ); therefore, the simpler model (symmetrical) is used in all subsequent analyses. For the niche breadth analysis, the best-performing model allows different variances in niche breadth values $(\sigma)$ and optimum niche breadth $(\theta)$ for annuals and perennials (OUMV; SI 13; average AIC weights $=0.79,0.72$, and 0.58 for PC1, PC2, and PC3, respectively). Two models compete as second-best model: (1) the OUM model that allows only optimum niche breadth $\left(\theta_{\mathrm{a}}\right.$ and $\left.\theta_{\mathrm{p}}\right)$ to differ between annuals and perennials and estimates a single common variance $(\sigma)$ in breadth values (average AIC weights $=0.034,0.17$, and 0.13 for PC1, PC2, and PC3, respectively) and (2) the OUMA model permits different strength of selection $\alpha_{\mathrm{a}}$ and $\alpha_{\mathrm{p}}$ between annual and perennial species (average AIC weights $=0.13,0.12$, and 0.21 for PC1, PC2, and PC3, respectively). The OUMV model confirms the presence of two distinct niche breadth optima for annual and perennial species, where niche breadth of perennials exceeds niche breadth of annuals by factors of 1.36, 1.33, and 1.43 for PC1, PC2, and PC3, respectively (fig. $4 a$ ). Further, this model reveals consid-

Figure 2: $a$, Phylogenetic trees for Eriogonoideae species (E., Eriogonum; C., Chorizanthe; P., Pterostegia), with molecular branch lengths (left) and branches proportional to time (right). Nodes with dots have bootstrap support $>80 \%$ and posterior probabilities $>0.9$. Nodes marked with arrows were calibrated with fossils during the dating analysis with BEAST, and dates indicated are the upper bounds of the calibration prior. Specific clades of Eriogonum and Chorizanthe genera are separated with dashed lines and labeled on the dated phylogeny. $b$, Molecular rates estimated separately for annual and perennial species. Branches of the phylogenetic tree are proportional to substitutions per site. Molecular rates are approximately 1.5 times higher in annuals than in perennials. Myr, million years. 

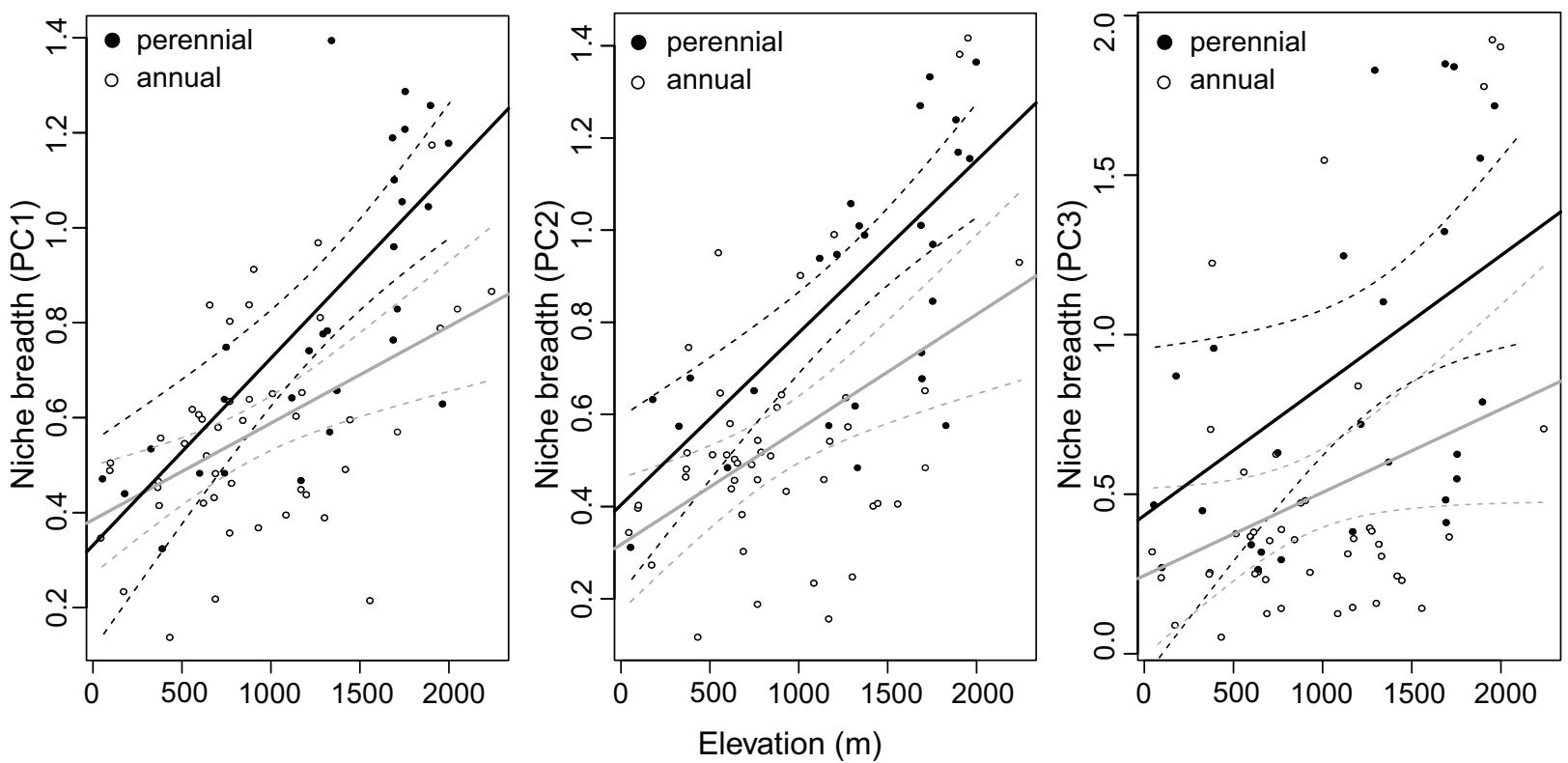

Figure 3: Phylogenetic generalized least squares results that estimate the linear relationship between niche breadth and elevation for scores on the three principal component (PC) axes. The fitted linear regression lines (solid lines) and confidence intervals (dashed lines) are presented independently for annuals (gray) and perennials (black). Scores on axis PC1 express niche breadth along the seasonality, isothermality, and mean annual temperature gradients; scores on PC2 represent niche breadth along the temperature and precipitation gradients; and scores on PC3 represent niche breadth along the precipitation and isothermality gradients.

erably higher rates of niche breadth evolution in perennial than in annual species by a factor of between 2 and 4 $\left(\chi^{2}=360.3,365.4\right.$, and 281.8 for PC1, PC2, and PC3, respectively; $\mathrm{df}=1$; all $P<.001$ ). For niche position analysis, the best-performing model differs depending on the ordination axes (SI 13), but across PC1 and PC2, niche position evolves faster in annual than in perennial species (fig. 4b). For PC1 and PC2, we find that models allowing different rate parameters $\sigma_{\mathrm{a}}$ and $\sigma_{\mathrm{p}}$ (BMS) and different rate and optimum parameters (OUMV), respectively, have the highest average AIC weights, while for PC3, the OU1 model with single niche position optimum $\theta$ shows the best fit (SI 13).

\section{Discussion}

The evolution of the ecological niche is a long-standing research topic in evolutionary biology and macroecology, with both fields offering complementary hypotheses and causal explanations. We examine the evolution of niche breadth in relation to elevation and latitude gradients while explicitly accounting for effects of life-history variation in generation time. We contrast interspecific evolutionary rates of niche evolution, which are more rapid in annuals, to rates of intraspecific niche evolution (evolution of niche breadth) that are higher in perennials, thus accommo- dating both macro- and microevolutionary perspectives on niche variation. Our results suggest that both environmental gradients and life-history strategies influence rates and patterns of niche breadth evolution. Life-history variation, here expressed as annual and perennial habits, can be strongly associated with evolutionary patterns in niche position and niche breadth.

\section{Testing Macroecological Hypotheses of Niche Breadth Evolution}

Niche breadth of Eriogonoideae species increases with elevation (fig. 3). In plant-pollinator interactions in buprestids (Pellissier et al. 2012; Rasmann et al. 2014), a similar trend of increasing ecological generalization with elevation is associated with greater abiotic (temperature, precipitation, and wind) and biotic (vegetation cover) environmental variability. More generally, environmental stability, environmental predictability, and environmental stress can determine patterns of niche specialization (Menge and Sutherland 1976). For instance, in marine soft-sediment faunal communities arranged over gradients of decreasing environmental stress, the most ecologically stable assemblages are the most complex ones and are characterized by a large number of stenotopic species (Menge and Sutherland 1976). Similarly, in Eriogonoideae 
Table 2: Relationship between niche breadth and elevation depending on life-history trait in Eriogonoideae species

\begin{tabular}{|c|c|c|c|c|c|}
\hline $\begin{array}{l}\text { Dependent variable, } \\
\text { covariates }\end{array}$ & Estimate & SE & $t$ & $F$ & $\begin{array}{c}\text { Adjusted } \\
R^{2}\end{array}$ \\
\hline \multicolumn{6}{|l|}{ PC1: } \\
\hline Elevation $_{\mathrm{a}}$ & $2.3703 \mathrm{E}-04$ & $6.7236 \mathrm{E}-05$ & $3.525^{* *}$ & 30.12 & .4726 \\
\hline Elevation $_{p}$ & $1.7290 \mathrm{E}-04$ & $5.1432 \mathrm{E}-05$ & $3.362^{* *}$ & & \\
\hline \multicolumn{6}{|l|}{ PC2: } \\
\hline Elevation $_{\mathrm{a}}$ & $2.6131 \mathrm{E}-04$ & $7.7699 \mathrm{E}-05$ & $3.363^{* *}$ & 26.8 & .4426 \\
\hline Elevation $_{\mathrm{p}}$ & $1.8621 \mathrm{E}-04$ & $5.9436 \mathrm{E}-05$ & $3.133^{* *}$ & & \\
\hline \multicolumn{6}{|l|}{ PC3: } \\
\hline Elevation $_{\mathrm{a}}$ & .00029446 & .00016711 & 1.762 . & 7.66 & .17 \\
\hline Elevation $_{p}$ & .00021870 & .00012783 & 1.711. & & \\
\hline
\end{tabular}

Note: Statistical results from the phylogenetic GLM models of the relationship between niche breadth and elevation. Elevation ${ }_{\mathrm{a}}$ denotes a slope parameter between elevation and the niche breadth of annual species. Elevation $n_{p}$ denotes the same but for perennial species, having accounted for annual species. The estimated $t$ value is significant for annual species (Elevation $n_{\mathrm{a}}$ ) and confirms positive association between niche breadth and elevation across all principal component axes. Further, there is a significant difference in slope estimates between annual and perennial species, since the estimated $t$ value is significant for perennials $\left(\right.$ Elevation $_{\mathrm{p}}$ ) relative to annuals $\left(\right.$ Elevation $_{\mathrm{a}}$ ).

** $P<.01$.

species, broad environmental generalists are typically found at higher elevations (figs. 1, 3), which in southwestern North America exhibit less climatic stability and predictability than found at lower elevations (Schoenherr 1995). Furthermore, high-elevation conditions of the Sierra Nevada and other mountain ranges may be favorable for climatic generalization in eriogonoid species. Conversely, as the climate becomes milder with decreasing elevation, niche specialization is a progressively more successful strategy for eriogonoids, similar to the pattern exhibited by species found along a transect of 14 flowerherbivore communities across central California (Moldenke 1975).

In contrast to niche variation over elevation, we find no evidence for increasing niche breadth with latitude (SI 12), as proposed in the latitude-niche breadth hypothesis (MacArthur 1965). For instance, Vázquez and Stevens (2004) - in their meta-analysis of 12 major taxa of mammals, birds, and insects-conclude that in its classical form, this hypothesis still lacks evidence from experimental studies. However, niche breadth in insects, measured in terms of its spatial (geographic range size) and biological (host specificity) components (Krasnov et al. 2008) and physiological tolerances (Addo-Bediako et al. 2000), increases with increasing latitude. This suggests that the latitude-niche breadth hypothesis holds for some species groups but not for others. Further, in our study, the latitudinal span of perennial species generally overlaps with the latitudinal span of annual species (fig. 1). The lack of support for the latitude-niche breadth hypothesis that we find may reflect the restricted latitudinal range of Eriogonoideae species, which in our study span from $32^{\circ} \mathrm{N}$ to $45^{\circ} \mathrm{N}$. Furthermore, our representative sample includes a quarter of species from the Eriogonodeae subfamily; therefore, expanded analyses or focus on other taxa may be needed to fully understand the interaction between latitude, elevation, and species niche. For instance, other groups with a larger latitudinal range, perhaps spanning both the temperate zone and the tropics, might demonstrate support for the latitude-niche breadth hypothesis.

\section{Life-History Traits Alter Interactions of Niche Breadth with Elevation}

The pace at which niche breadth increases with elevation differs between annual and perennial species (fig. 3). First, perennials are generally confined to higher elevations (fig. 1) and are, in general, more frequent above $2,000 \mathrm{~m}$ when compared with annuals. Second, the niche breadth of perennials responds more strongly to increasing elevation than that of annuals (fig. 3). This may suggest that perennial eriogonoids are better adapted to higher elevation as a result of some morphological or physiological traits that permit them to survive short growing seasons and seasonal variability at higher elevations. Most perennial erigonoids have resistant and regenerative somatic tissue and can be classified ecologically into either hemicryptophyte or chamaephyte life forms, in which overwintering buds are at or near the soil level, respectively (Raunkiær classification; Raunkiær 1904). These two forms are usually associated with a shift into arctic and alpine tundra, where hemicryptophytes dominate florae in moist to humid temperate areas, and chamaephytes are frequent in flora of high latitudes and elevations. While we focus on the re- 
a

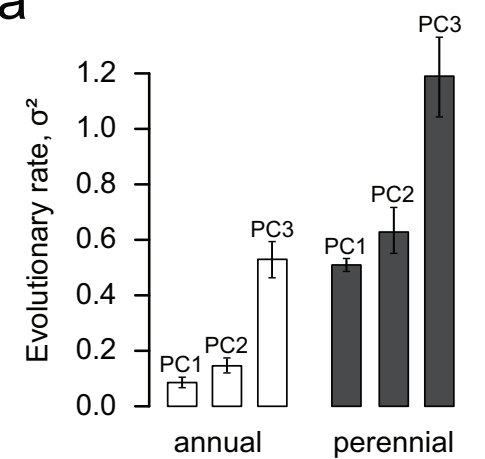

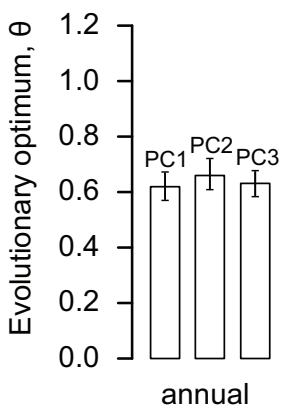

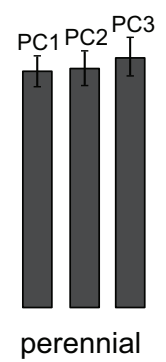

b

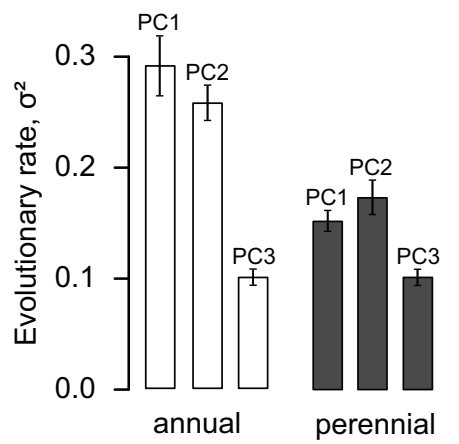

Parameter estimates of the evolutionary models for niche breadth (a) and niche position (b) of annual and perennial species

Figure 4: $a$, Parameter estimates for the OUMV model (different rates $\sigma^{2}$ and optima $\theta$ between annual and perennial species) for the evolution of niche breadth show that perennials are characterized by higher evolutionary rates and broader optimum niche breadths compared with annuals across all principal component (PC) axes. $b$, Parameter estimates for the BMS/OUMV models (different rates $\sigma^{2}$ ) show that niche position of annuals evolves more rapidly compared with that of perennials (note that for PC3, the rate is estimated with the OU1 model).

lationship between perennial versus annual strategies and niche breadth, additional factors-such as effective population size (Kassen 2002), longevity, presence of a seed bank, seed size (Aizen and Patterson 1990), type (Edwards and Westoby 1996), and number-could be involved in evolutionary processes that influence intraspecific niche variation. Further studies may illuminate the relative adaptive performance across environmental gradients by annual and perennial Eriogonoideae species in southwestern North America.

\section{Rates of Interspecific Evolution Are Higher in Annual Species}

Recent results show that rates of interspecific evolution of climatic niche in angiosperms are two to 10 times faster in herbaceous than in woody life forms (Smith and Beaulieu 2009). Further, rates of morphological divergence in small mammals (rodents) are four to 11 times higher compared with larger mammal species with longer generation times (Martin and Palumbi 1993). This suggests that lifehistory attributes, such as generation time, can impose limits to the evolution of phenotypic tolerances. In Eriogonoideae, we find that rates of interspecific niche evolution are higher in annual species (fig. 4b). In annual eriogonoids, evolution of niche position occurs most rapidly along the temperature seasonality/isothermality gradient (PC1) and, to a lesser extent, along the temperature/ precipitation gradient (PC2). On the one hand, these differences in the evolutionary rates of niche position might reflect the differences in molecular substitution rates and differential generation time, similar to the patterns of cou- pled phenotypic and molecular evolution found in vascular plants (Davies et al. 2006) and in woody lineages (Smith and Beaulieu 2009). On the other hand, the differential patterns of interspecific evolution in Eriogonoideae may be driven by the high level of endemism that is particularly common in drought-adapted annuals in this subfamily (Reveal 1989). The evolutionary processes responsible for the greater endemism in annual species remain obscure, but complex landscape and climatic heterogeneity should promote niche specialization and speciation in the group (Raven and Axelrod 1978). Further, flowering phenology may also contribute to ecological diversification of annual eriogonoids because sympatric species typically shift pollinators during habitat diversification and speciation (Levin 2006).

\section{Perennials Exceed Annuals in Rates of Niche Breadth Evolution}

Species differ considerably in their degree of ecological specialization (Fox and Morrow 1981), and estimates of rates of niche breadth evolution should help to characterize niche evolution in general. In Eriogonoideae, estimates of rates of niche breadth evolution display the opposite pattern compared with estimates of the rate of evolution of niche position. Not only are perennial species characterized by $50 \%$ wider climatic niche than annual species (SI $11 \mathrm{~b})$, but also rates of niche breadth evolution are two to four times faster in perennials than in annuals (fig. 4a). Our analysis shows that tree branches corresponding to perenniality are on average younger than branches corresponding to annuality (fig. $2 a$, stochastic mapping, tree 
on the right). The higher rate of niche breadth evolution in perennial clades is also accompanied by a shift into colder environments with abundant rainfall and, typically, higher elevation (SI 11a; PC2). Phylogenetic dating of Eriogonoideae species suggests that this pattern may be associated with species range expansion into novel climatic niches following climatic cool down (Lourens et al. 2004) during the middle and late Miocene and Plio-Pleistocene $(<10$ million years ago; fig. $2 a)$. This was perhaps coupled with the acquisition of perenniality that permitted necessary physiological and morphological adaptations to shorter growing seasons and limited energy at high elevations (Raven and Axelrod 1978). Detection of complex phylogeographic patterns in perennial eriogonoids might provide evidence of ongoing speciation driven by climate cycling during the Pleistocene and Holocene, as has occurred in the Eriogonum corymbosum species complex (Ellis 2009). Annuals may have narrower niches because ecological variation has been partitioned among species, while in perennials this variation is partitioned among subspecific lineages in the process of ongoing speciation.

\section{From Microevolutionary Dynamics to Macroecological Patterns}

We suggest that there are at least three sets of factors that influence the evolution of niche breadth in the Eriogonoidae. First, and as discussed above, abiotic environ- mental factors across spatial and temporal heterogeneities, such as those associated with elevation, provide the necessary background for selective forces to act on niche expansion and contraction. Second, generation time is associated with the evolution of niche breadth across a gradient of increasing elevation. Nonetheless, the selective mechanisms that link generation time to the evolution of niche breadth remain unclear. Putatively, increased substitution rates, typical for short-generation species, could remove nearly neutral and deleterious alleles more rapidly in annuals than in perennials, thus accelerating rates of adaptation and niche specialization (Lynch 2007; Sloan et al. 2012). Consequently, rates of niche specialization should proceed faster in annual species than in perennials when the environment is homogeneous (Whitlock 1996; Kassen 2002). This is reflected in our analysis by higher rates of interspecific niche position evolution in annual than in perennial eriogonoids. In contrast, slower rates (per unit time) of removal of nearly neutral or slightly deleterious alleles in perennial species might leave extensive standing variation at the relevant loci for long periods, even though loss of allelic diversity per generation might not differ between annuals and perennials (Whitlock 1996; Baer et al. 2007). Arguably, the fitness costs of such standing variation in temporally constant environments are substantial (Kassen 2002), while in temporally heterogeneous environments this variation could be removed more slowly, increasing chances of the survival of generalists

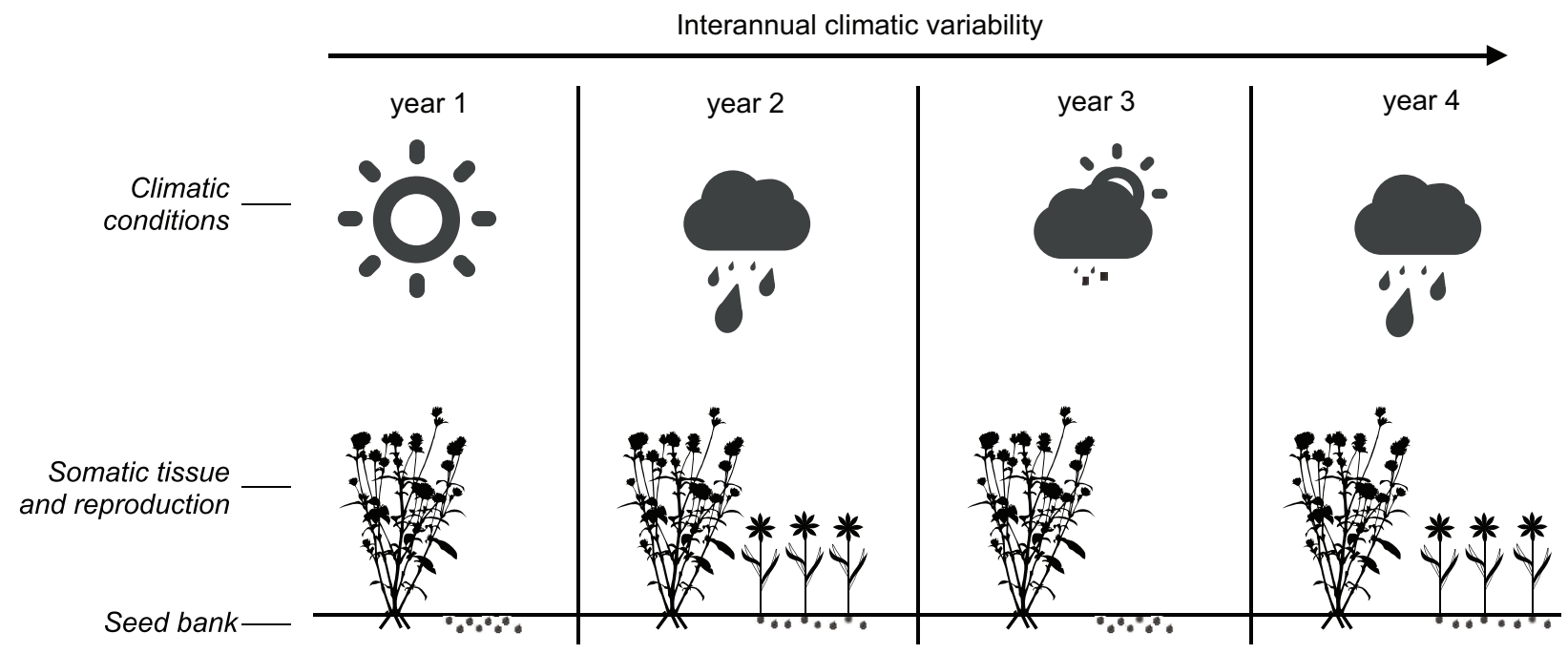

Figure 5: Schematic representation of one hypothesis for the maintenance of broader climatic niche tolerances in perennials than in annuals, in which the interannual variability experienced by perennials exposes them to more diverse regimes that may select for environmental tolerance. Annuals here have a single flowering stem, while the perennial species have several. The figure shows four consecutive years over which a perennial species is exposed to a broad range of climatic conditions. In contrast, annual species germinate only under favorable conditions for growth and reproduction during specific years, indicated here by the rainy cloud, and remain dormant in the seed bank during unfavorable years. 
(Whitlock 1996; Kassen 2002). We cannot ascribe interspecific differences in niche breadth to heritable variation in environmental tolerance within species. Consequently, a species might have a broad niche as a result of a ubiquitous genotype with broad environmental tolerance, in the absence of intraspecific variation in tolerance (Futuyma and Moreno 1988). However, the near ubiquity of local adaptation of plants to environment (e.g., Savolainen et al. 2007) suggests the existence of heritable variation in environmental optima within populations. Nonetheless, an advantage of a broader niche is evident in recent range expansions (Holt 2003), where negative genetic correlation in fitness across heterogeneous landscape patches has not yet evolved in response to selection for specialization.

Third, the differences in rates of accumulation of niche variance between annual and perennial species could also be related to the differences in strength of selection rather than mutation rates and generation times. Such differential selection strength could occur through changes in population size (Bolnick et al. 2011; Walser and Haag 2012) or as a result of the maintenance of specific ecological adaptations in one life-history class compared with the other one (Templeton and Levin 1979). For example, in xeric habitat annuals, formation of a seed bank may serve as an evolutionary filter that causes only a few years from the reproductive cycle to have any true evolutionary impact and to effectively eliminate the selective impact of other years (fig. 5). Soil seed banks greatly reduce the fitness uncertainty generated by cyclical or random environments and free the plant population from having to respond genetically to the fitness conditions realized in every year. In such case, any increase in niche breadth would be quickly wiped away as a result of strong selection on niche breadth and would promote higher rates of evolution in niche position in annual species (Templeton and Levin 1979; Baskin et al. 1993). Our results show (SI 13) that the model including differential selection strength between annuals and perennials is the second-best-supported model after the model with different rates and optima of niche breadth evolution. This suggests that in the Eriogonoideae, differential selection might compete with or complement the model with differential evolutionary rates and optima. Empirically distinguishing between the effects of generation time and selection strength is currently difficult because of the lack of experimental data on seed dormancy and seed banks of both xeric annuals and higher-elevation perennials (Marlette and Anderson 1986; Philippi 1993). In addition, generation time differences, effects of seed pools, and changes in population size are not likely independent (Venable and Brown 1988; Hartl and Clark 1997; Venable 2007) and, thus, could all influence the evolution of niche breadth and position. Field experiments would be necessary to determine the relative contribution of these mechanisms to the evolution of niche breadth.

\section{Conclusion}

Niche evolution in the eriogonoids appears to have led to partitioning of environmental tolerance among annual species, while environmental tolerance in perennial species has accumulated within species. It remains unclear whether mechanisms specific to annuals promote reproductive isolation as lineages accrue environmental tolerance or whether mechanisms specific to perennials promote species cohesion. Additional life-history traits should be considered when testing rates of niche evolution, since they may illuminate dependencies between organismal properties, breadth of environmental tolerance, and its evolutionary lability.

\section{Acknowledgments}

We would like to thank S. Boyd, T. Columbus, and T. A. Schweich for fieldwork and collection of sample tissues and S. Boyd and E. Kempton for providing valuable discussion on Eriogonoideae phylogeny and helping with specimen identification. We are grateful to J. Davies, R. Holt, M. L. Serrano, and two anonymous reviewers for comments and critique that led to improvement of earlier versions of the manuscript. We thank D. Savova-Bianchi for help with DNA sequencing and P. Lunin for constructive comments on figures. The Vital-IT facilities of the Swiss Institute of Bioinformatics were used for all computational aspect of this study. The project was supported by Swiss National Science Foundation grants 3100A0-122433 and 3100A0-138282 to P.B.P. and N.S., respectively.

\section{Literature Cited}

Addo-Bediako, A., S. L. Chown, and K. J. Gaston. 2000. Thermal tolerance, climatic variability and latitude. Proceedings of the Roval Society B: Biological Sciences 267:739-745.

Aizen, M. A., and W. A. Patterson III. 1990. Acorn size and geographical range in the North American oaks (Quercus L.). Journal of Biogeography 17:327-332.

Andreasen, K., and B. G. Baldwin. 2001. Unequal evolutionary rates between annual and perennial lineages of checker mallows (Sidalcea, Malvaceae): evidence from 18S-26S rDNA internal and external transcribed spacers. Molecular Biology and Evolution 18: 936-944.

Baer, C. F., M. M. Miyamoto, and D. R. Denver. 2007. Mutation rate variation in multicellular eukaryotes: causes and consequences. Nature Reviews Genetics 8:619-631.

Barfield, M., R. D. Holt, and R. Gomulkiewicz. 2011. Evolution in stage-structured populations. American Naturalist 177:397-409. 
Baskin, C. C., P. L. Chesson, and J. M. Baskin. 1993. Annual seed dormancy cycles in two desert winter annuals. Journal of Ecology 81:551-556.

Beaulieu, J. M., D.-C. Jhwueng, C. Boettiger, and B. C. O'Meara. 2012. Modeling stabilizing selection: expanding the OrnsteinUhlenbeck model of adaptive evolution. Evolution 66:2369-2383.

Bennett, A. F., and R. E. Lenski. 2007. An experimental test of evolutionary trade-offs during temperature adaptation. Proceedings of the National Academy of Sciences of the USA 104:8649-8654.

Bernstein, R. A., and M. Gobbel. 1979. Partitioning of space in communities of ants. Journal of Animal Ecology 48:931-942.

Bolnick, D. I., P. Amarasekare, M. S. Araújo, R. Bürger, J. M. Levine, M. Novak, V. H. W. Rudolf, et al. 2011. Why intraspecific trait variation matters in community ecology. Trends in Ecology and Evolution 26:183-192.

Bolnick, D. I., R. Svanbäck, J. A. Fordyce, L. H. Yang, J. M. Davis, C. D. Hulsey, and M. L. Forister. 2003. The ecology of individuals: incidence and implications of individual specialization. American Naturalist 161:1-28.

Breiman, L. 2001. Random forests. Machine Learning 45:5-32.

Breiman, L., and A. Cutler. 2012. randomForest. http://cran .r-project.org/web/packages/randomForest/index.html.

Brown, J., and N. Pavlovic. 1992. Evolution in heterogeneous environments: effects of migration on habitat specialization. Evolutionary Ecology 6:360-382.

Butler, M. A., and A. A. King. 2004. Phylogenetic comparative analysis: a modeling approach for adaptive evolution. American Naturalist 164:683-695.

Caitlin Fisher-Reid, M., K. H. Kozak, and J. J. Wiens. 2012. How is the rate of climatic-niche evolution related to climatic-niche breadth? Evolution 66:3836-3851.

Cavender-Bares, J., K. H. Kozak, P. V. A. Fine, and S. W. Kembel. 2009. The merging of community ecology and phylogenetic biology. Ecology Letters 12:693-715.

Colwell, R. K., and D. J. Futuyma. 1971. On the measurement of niche breadth and overlap. Ecology 52:567-576.

Cutler, D. R., T. C. Edwards, K. H. Beard, A. Cutler, K. T. Hess, J. Gibson, and J. J. Lawler. 2007. Random forests for classification in ecology. Ecology 88:2783-2792.

Davies, T. J., V. Savolainen, and P. Soltis. 2006. Neutral theory, phylogenies, and the relationship between phenotypic change and evolutionary rates. Evolution 60:476-483.

Doledec, S., D. Chessel, and C. Gimaret-Carpentier. 2000. Niche separation in community analysis: a new method. Ecology 81: 2914-2927.

Dray, S., and A. B. Dufour. 2007. The ade4 package: implementing the duality diagram for ecologists. Journal of Statistical Software 22:1-20.

Drummond, A., and A. Rambaut. 2007. BEAST: Bayesian evolutionary analysis by sampling trees. BMC Evolutionary Biology 7: 214.

Duminil, J., O. Hardy, and R. Petit. 2009. Plant traits correlated with generation time directly affect inbreeding depression and mating system and indirectly genetic structure. BMC Evolutionary Biology 9:177.

Edwards, W., and M. Westoby. 1996. Reserve mass and dispersal investment in relation to geographic range of plant species: phylogenetically independent contrasts. Journal of Biogeography 23: 329-338.

Ellis, M. W. 2009. Speciation, species concepts, and biogeography illustrated by a buckwheat complex (Eriogonum corymbosum). $\mathrm{PhD}$ diss. Utah State University, Logan. http://digitalcommons.usu.edu letd/370.

Evans, M., S. Smith, R. Flynn, and M. Donoghue. 2009. Climate, niche evolution, and diversification of the "bird-cage" evening primroses (Oenothera, sections Anogra and Kleinia). American Naturalist 173:225-240.

Felsenstein, J. 1985. Phylogenies and the comparative method. American Naturalist 125:1-15.

Fox, L. R., and P. A. Morrow. 1981. Specialization: species property or local phenomenon? Science 211:887-893.

Freeman, C. C. 2005. Magnoliophyta: Caryophyllidae, part 2. Flora of North America: North of Mexico. Vol. 5. Oxford University Press, New York.

Futuyma, D. J., and G. Moreno. 1988. The evolution of ecological specialization. Annual Review of Ecology and Systematics 19:207233.

Gaston, K. J. 1994. Measuring geographic range sizes. Ecography 17: 198-205.

Guindon, S., F. Delsuc, J.-F. Dufayard, and O. Gascuel. 2009. Estimating maximum likelihood phylogenies with PhyML. Pages 113137 in D. Posada, ed. Bioinformatics for DNA sequence analysis. Methods in Molecular Biology 537. Humana, Totowa, NJ.

Hamrick, J. L., Y. B. Linhart, and J. B. Mitton. 1979. Relationships between life history characteristics and electrophoretically detectable genetic variation in plants. Annual Review of Ecology and Systematics 10:173-200.

Hansen, T. F. 1997. Stabilizing selection and the comparative analysis of adaptation. Evolution 51:1341-1351.

Hartl, D. L., and A. G. Clark. 1997. Principles of population genetics. Vol. 116. Sinauer, Sunderland, MA.

Hijmans, R. J., S. E. Cameron, J. L. Parra, P. G. Jones, and A. Jarvis. 2005. Very high resolution interpolated climate surfaces for global land areas. International Journal of Climatology 25:1965-1978.

Hijmans, R., and J. van Etten. 2012. raster: geographic analysis and modeling with raster data. http://cran.r-project.org/web/packages /raster/index.html.

Holt, R. D. 1992. Analysis of adaptation in heterogeneous landscapes: implications for the evolution of fundamental niches. Evolutionary Ecology 6:433-447.

- 2003. On the evolutionary ecology of species' ranges. Evolutionary Ecology Research 5:159-178.

Hutchinson, G. E. 1957. Concluding remarks. Cold Spring Harbor Symposium Quantitative Biology 22:415-427.

Ingram, T., L. J. Harmon, and J. B. Shurin. 2009. Niche evolution, trophic structure, and species turnover in model food webs. American Naturalist 174:56-67.

Kassen, R. 2002. The experimental evolution of specialists, generalists, and the maintenance of diversity. Journal of Evolutionary Biology 15:173-190.

Katoh, K., and H. Toh. 2008. Recent developments in the MAFFT multiple sequence alignment program. Briefings in Bioinformatics 9:286-298.

Kawecki, T. J. 2000. Adaptation to marginal habitats: contrasting influence of the dispersal rate on the fate of alleles with small and large effects. Proceedings of the Royal Society B: Biological Sciences 267:1315-1320.

Keitt, T., R. Bivand, E. Pebesma, and B. Rowlingson. 2012. rgdal: bindings for the geospatial data abstraction library. http://cran .r-project.org/web/packages/rgdal/index.html. 
Kempton, E. A. 2012. Systematics of Eriogonoideae s. s. (Polygonaceae). Systematic Botany 37:723-737.

Kocher, T. D. 2004. Adaptive evolution and explosive speciation: the cichlid fish model. Nature Reviews Genetics 5:288-298.

Kostikova, A., G. Litsios, N. Salamin, and P. B. Pearman. 2013. Data from: Linking life-history traits, ecology, and niche breadth evolution in North American eriogonoids (Polygonaceae). American Naturalist, Dryad Digital Repository, http://dx.doi.org/10.5061 /dryad.46kv1.

Kozak, K. H., and J. J. Wiens. 2010. Niche conservatism drives elevational diversity patterns in Appalachian salamanders. American Naturalist 176:40-54.

Krasnov, B. R., G. I. Shenbrot, I. S. Khokhlova, D. Mouillot, and R. Poulin. 2008. Latitudinal gradients in niche breadth: empirical evidence from haematophagous ectoparasites. Journal of Biogeography 35:592-601.

Lanfear, R., S. Y. W. Ho, D. Love, and L. Bromham. 2010. Mutation rate is linked to diversification in birds. Proceedings of the National Academy of Sciences of the USA 107:20423-20428.

Levin, D. A. 2006. Flowering phenology in relation to adaptive radiation. Systematic Botany 31:239-246.

Losos, J. B., and R. E. Ricklefs. 2009. Adaptation and diversification on islands. Nature 457:830-836.

Lourens, L., F. Hilgen, N. J. Shackleton, J. Laskar, and D. Wilson. 2004. The Neogene period. Pages 409-440 in F. Gradstein, J. Ogg, and A. G. Smith, eds. A geologic time scale 2004. Cambridge University Press, Cambridge.

Lynch, M. 2007. The frailty of adaptive hypotheses for the origins of organismal complexity. Proceedings of the National Academy of Sciences of the USA 104:8597-8604.

MacArthur, R. H. 1965. Patterns of species diversity. Biological Reviews 40:510-533.

- 1972. Geographical ecology. Princeton University Press, Princeton, NJ.

Marlette, G. M., and J. E. Anderson. 1986. Seed banks and propagule dispersal in crested-wheatgrass stands. $\underline{\text { Journal of Applied Ecology }}$ 23:161-175.

Martin, A. P., and S. R. Palumbi. 1993. Body size, metabolic rate, generation time, and the molecular clock. Proceedings of the National Academy of Sciences of the USA 90:4087-4091.

Menge, B. A., and J. P. Sutherland. 1976. Species diversity gradients: synthesis of the roles of predation, competition, and temporal heterogeneity. American Naturalist 110:351-369.

Moldenke, A. R. 1975. Niche specialization and species diversity along a California transect. Oecologia (Berlin) 21:219-242.

Nicodemus, K., J. Malley, C. Strobl, and A. Ziegler. 2010. The behaviour of random forest permutation-based variable importance measures under predictor correlation. BMC Bioinformatics 11: 1471-2105.

O’Meara, B. C., C. Ané, M. J. Sanderson, and P. C. Wainwright. 2006. Testing for different rates of continuous trait evolution using likelihood. Evolution 60:922-933.

Orme, C. D. L., R. P. Freckleton, G. H. Thomas, T. Petzoldt, and S. A. Fritz. 2011. Caper: comparative analyses of phylogenetics and evolution in R. http://r-forge.r-project.org/projects/caper.

Paradis, E., J. Claude, and K. Strimmer. 2004. APE: analyses of phylogenetics and evolution in R language. Bioinformatics 20:289290.

Pearman, P. B., M. D’Amen, C. H. Graham, W. Thuiller, and N. E. Zimmermann. 2010. Within-taxon niche structure: niche conser- vatism, divergence and predicted effects of climate change. Ecography 33:990-1003.

Pellissier, L., G. Litsios, K. Fiedler, J. Pottier, A. Dubuis, J.-N. Pradervand, N. Salamin, and A. Guisan. 2012. Loss of interactions with ants under cold climate in a regional myrmecophilous butterfly fauna. Journal of Biogeography 39:1782-1790.

Philippi, T. 1993. Bet-hedging germination of desert annuals: beyond the first year. American Naturalist 142:474-487.

Pianka, E. R. 1974. Niche overlap and diffuse competition. Proceedings of the National Academy of Sciences of the USA 71:21412145.

Rasmann, S., N. Alvarez, and L. Pellissier. 2014. The altitudinal niche breadth hypothesis in plant-insect interaction. In C. Voelckel and G. Jander, eds. Plant insect interactions. Annual Plant Reviews Series. Vol. 47. Wiley-Blackwell, Oxford.

Raunkiær, C. 1904. Om biologiske Typer, med Hensyn til Planternes Tilpasninger til at overleve ugunstige Aarstider. Botanisk Tidsskrift 26:XIV.

Raven, P. H., and D. I. Axelrod. 1978. Origin and relationships of the California flora. University of California Press, Berkley.

R Development Core Team. 2011. R: a language and environment for statistical computing. R Foundation for Statistical Computing, Vienna.

Reveal, J. L. 1978. Distribution and phylogeny of Eriogonoideae. Great Basin Naturalist Memoirs 2:169-190.

- 1989. The eriogonoid flora of California (Polygonaceae: Eriogonoideae). Phytologia 66:295-414.

Revell, L. J. 2012. phytools: an R package for phylogenetic comparative biology (and other things). Methods in Ecology and Evolution 3:217-223.

Ripley, B. 2012. Tree: classification and regression trees. http://cran .r-project.org/web/packages/tree/index.html.

Ronquist, F., and J. P. Huelsenbeck. 2003. MrBayes 3: Bayesian phylogenetic inference under mixed models. Bioinformatics 19:15721574.

Salisbury, C. L., N. Seddon, C. R. Cooney, and J. A. Tobias. 2012. The latitudinal gradient in dispersal constraints: ecological specialisation drives diversification in tropical birds. Ecology Letters 15:847-855.

Sanchez, A., and K. A. Kron. 2008. Phylogenetics of Polygonaceae with an emphasis on the evolution of Eriogonoideae. Systematic Botany 33:87-96.

Savolainen, O., T. Pyhajarvi, and T. Knurr. 2007. Gene flow and local adaptation in trees. Annual Review of Ecology, Evolution, and Systematics 38:595-619.

Schoenherr, A. 1995. A natural history of California. University of California Press, Berkeley.

Sloan, D. B., A. J. Alverson, J. P. Chuckalovcak, M. Wu, D. E. McCauley, J. D. Palmer, and D. R. Taylor. 2012. Rapid evolution of enormous, multichromosomal genomes in flowering plant mitochondria with exceptionally high mutation rates. PLoS Biology 10:e1001241.

Smith, S. A., and J. M. Beaulieu. 2009. Life history influences rates of climatic niche evolution in flowering plants. Proceedings of the Roval Society B: Biological Sciences 276:4345-4352.

Soria-Hernanz, D., O. Fiz-Palacios, J. Braverman, and M. Hamilton. 2008. Reconsidering the generation time hypothesis based on nuclear ribosomal ITS sequence comparisons in annual and perennial angiosperms. BMC Evolutionary Biology 8:344.

Strobl, C., A.-L. Boulesteix, T. Kneib, T. Augustin, and A. Zeileis. 
2008. Conditional variable importance for random forests. BMC Bioinformatics 9:1471-2105.

Swets, J. A. 1988. Measuring the accuracy of diagnostic systems. Science 240:1285-1293.

Talavera, G., and J. Castresana. 2007. Improvement of phylogenies after removing divergent and ambiguously aligned blocks from protein sequence alignments. Systematic Biology 56:564-577.

Templeton, A. R., and D. A. Levin. 1979. Evolutionary consequences of seed pools. American Naturalist 114:232-249.

Thode, H. C. 2002. Testing for normality. Marcel Dekker, New York. Thuiller, W., S. Lavorel, G. F. Midgley, S. Lavergne, and A. G. Rebelo. 2004. Relating plant traits and species distributions along bioclimatic gradients for 88 Leucadendron species in the Cape Floristic Region. Ecology 85:1688-1699.

Tsantes, C., and M. E. Steiper. 2009. Age at first reproduction explains rate variation in the strepsirrhine molecular clock. Proceedings of the National Academy of Sciences of the USA 106:18165-18170.

Urbanski, J., M. Mogi, D. O’Donnell, M. DeCotiis, T. Toma, and P. Armbruster. 2012. Rapid adaptive evolution of photoperiodic response during invasion and range expansion across a climatic gradient. American Naturalist 179:490-500.

Vázquez, D. P., and R. D. Stevens. 2004. The latitudinal gradient in niche breadth: concepts and evidence. American Naturalist 164: $1-19$.
Venable, D. L. 2007. Bet hedging in a guild of desert annuals. Ecology 88:1086-1090.

Venable, D. L., and J. S. Brown. 1988. The selective interactions of dispersal, dormancy, and seed size as adaptations for reducing risk in variable environments. American Naturalist 131:360-384.

Walser, B., and C. R. Haag. 2012. Strong intraspecific variation in genetic diversity and genetic differentiation in Daphnia magna: the effects of population turnover and population size. Molecular Ecology 21:851-861.

Whitlock, M. C. 1996. The red queen beats the jack-of-all-trades: the limitations on the evolution of phenotypic plasticity and niche breadth. American Naturalist 148(suppl.):S65-S77.

Whittle, C.-A., and M. O. Johnston. 2003. Broad-scale analysis contradicts the theory that generation time affects molecular evolutionary rates in plants. Journal of Molecular Evolution 56:223233.

Wright, S. 1932. The roles of mutation, inbreeding, crossbreeding, and selection in evolution. Pages 355-366 in D. F. Jones, ed. Proceedings of the Sixth International Congress on Genetics. Brooklyn Botanic Garden, Brooklyn.

Associate Editor: Jana C. Vamosi Editor: Susan Kalisz

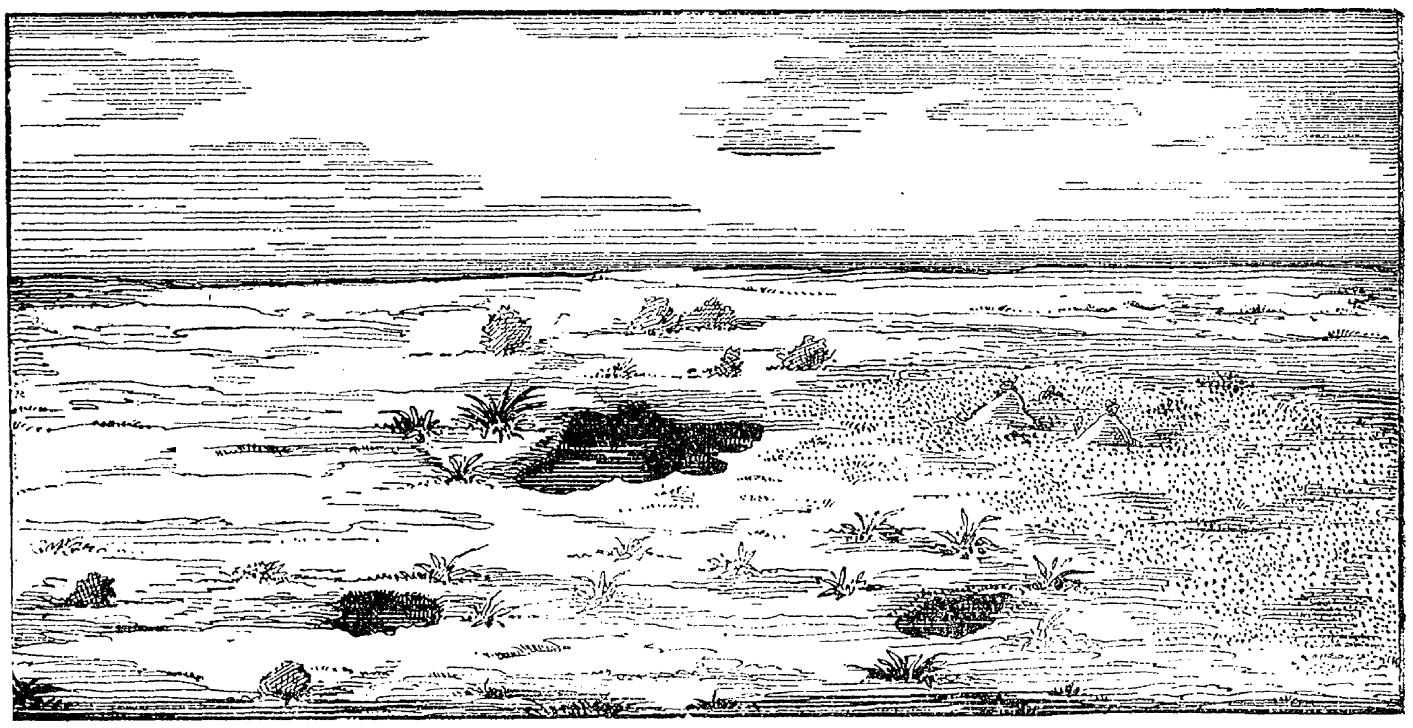

"To those who have experienced the pangs of thirst, while journeying over the desolate wastes that characterize this section, it will not be surprising that reminiscences of water should linger longest in the memory of the traveler. In fact the procurement of that necessity is a matter of such vital importance that all movements are subordinated and controlled by the answer to the question, 'Is there any water there?"” From “The Springs of Southern Nevada” by D. A. Lyle (American Naturalist, 1878, 12:18-27). 